\title{
Evaluation of Gellan Gum Film Containing Virgin Coconut Oil for Transparent Dressing Materials
}

\author{
Nur Arifah Ismail, ${ }^{1}$ Siti Fatimah Mohamad, \\ Maizatul Akma Ibrahim, ${ }^{2}$ and Khairul Anuar Mat Amin ${ }^{1,3}$ \\ ${ }^{1}$ School of Fundamental Sciences, University Malaysia Terengganu, 21030 Terengganu, Malaysia \\ ${ }^{2}$ Department of Plant Science, Kulliyyah of Science, International Islamic University Malaysia, Jalan Sultan Ahmad Shah, \\ Bandar Indera Mahkota, 25200 Kuantan, Pahang, Malaysia \\ ${ }^{3}$ Institute of Marine Biotechnology, University Malaysia Terengganu, 21030 Terengganu, Malaysia
}

Correspondence should be addressed to Khairul Anuar Mat Amin; kerol@umt.edu.my

Received 1 September 2014; Revised 10 December 2014; Accepted 11 December 2014; Published 30 December 2014

Academic Editor: Viness Pillay

Copyright (C) 2014 Nur Arifah Ismail et al. This is an open access article distributed under the Creative Commons Attribution License, which permits unrestricted use, distribution, and reproduction in any medium, provided the original work is properly cited.

\begin{abstract}
We examined the potential of virgin coconut oil (VCO) incorporated in gellan gum (GG) films as a dressing material. Pure GG film is extremely brittle and inclusion of $0.3 \%(\mathrm{w} / \mathrm{w})$ VCO in the GG film (GG-VCO3) improved the toughness $\left(T \approx 0.67 \pm 0.33 \mathrm{~J} \mathrm{~g}^{-1}\right)$ of the composite films. Swelling properties and water vapor transmission rates of GG-VCO composite films decreased, whereas thermal behavior values increased upon the addition of higher concentrations of VCO. Cell studies exhibit that the VCO is noncytotoxic to human skin fibroblast cells (CRL2522) with limited cell growth observed on GG-VCO3 films at 1,650 cells/well after incubation for $72 \mathrm{~h}$ which could be due to hydrophobic influence of the material surface. The qualitative and in vitro quantitative antibacterial results revealed that VCO does not possess strong bacterial resistance against all four tested bacteria, that is, two Gram-positive (Staphylococcus aureus and Staphylococcus epidermidis) and two Gram-negative bacteria (Pseudomonas aeruginosa and Proteus mirabilis).
\end{abstract}

\section{Introduction}

The development of wound care materials continues to cater to the various different needs of damaged skin problems. Biopolymers such as gellan gum (GG) have received great attention, particularly in the field of biomedicine, due to their biocompatibility and biodegradability properties. Gellan gum is produced by Pseudomonas elodea and consists of a repeating unit of tetrasaccharide: 1,3-linked $\beta$-D-glucose, 1,4-linked $\beta$ $\mathrm{D}$-glucuronic acid, 1,4-linked $\beta$-D-glucose, and 1,4-linked $\alpha$ L-rhamnose. Gellan gum has been approved by the United States Food and Drug Administration (US FDA) and the European Union (EU) labels it as E 415 in EU regulation for the use in food industry. It is currently popular in the development of tissue engineering. Studies on medical and pharmaceutical applications of gellan gum have also been reported which include "dual layer films" [1], bioink substrates for printing living cells [2], use for dressing material
[3], and use as a vehicle for ophthalmic drugs [4]. Besides that, gellan gum demonstrates good compatibility with live cells such as mouse fibroblast (L929 cell line), human dermal fibroblasts (HDFs), human fetal osteoblasts (hFOBs 1.19), human nasal cartilage, and rat bone marrow cells (rBMC) $[1,5-7]$.

On the other hand, virgin coconut oil (VCO) is one of the recent promising candidates in promoting healing process due to its biocompatibility property and antibacterial activities. Previous studies reported that pure VCO examined through in vivo test could enhance the healing process. Nevin and Rajamohan reported that the treated wound of a size of $4 \mathrm{~cm}^{2}$ on young rats with $1.0 \mathrm{~mL}$ VCO healed much faster by giving a decreased time of complete epithelisation [8]. Intahphuak and coworkers proved that VCO which is orally administered in an equivalent volume of $0.5 \mathrm{~mL} / 100 \mathrm{~g}$ body weight of the rats showed a significant result in reducing inflammatory effect in acute and chronic 
inflammation on ethyl phenylpropiolate-induced ear edema [9]. The anti-inflammatory and antinociceptive activities of pure VCO administered orally $(100 \mathrm{mg} / \mathrm{kg})$ have also been reported in male Balb-C mice and Sprague-Dawley rats [10]. In combating bacteria, Shilling and coworkers successfully demonstrated the growth inhibition of Clostridium difficile by fatty acids of VCO [11]. However, to our best knowledge, no study has been reported on the biocompatibility of VCO composite films through in vitro tests to be applied as one of the elements in wound dressing material. In this study, we describe the effect of VCO on mechanical and physical properties of the GG composite film. The cell viability and proliferation tests involved human fibroblast skin cell (CRL-2522, American Type Tissue Collection), while the antibacterial activities were assessed via in vitro qualitative and quantitative studies against four bacterial strains, that is, Gram-positive bacteria (Staphylococcus aureus and Staphylococcus epidermidis) and Gram-negative bacteria (Pseudomonas aeruginosa and Proteus mirabilis).

\section{Materials and Methods}

2.1. Materials and Film Formation. Low-acyl gellan gum (Gelzan CM, $M_{w} \approx 2-3 \times 10^{5} \mathrm{Da}$, product number G1910, and lot number SLBB0374V) and Triton X-102 (product number 1001318460 and lot number MKBDD4707V) were obtained from Sigma-Aldrich, Malaysia. The virgin coconut oil (VCO) (product number 617488-D) was obtained from BioNeutraceutical (M) Sdn. Bhd., and the commercial antibiotic, Norfloxacin (product number N9890), was from Fluka, USA. All materials were used as initially received.

The films were prepared by using casting method. A stock solution of gellan gum (GG) was made by dissolving $1 \%(\mathrm{w} / \mathrm{v})$ of GG in $100 \mathrm{~mL}$ deionized water $(18.2 \mathrm{M} \Omega$ ) with continuous stirring for $2 \mathrm{~h}$ at $70^{\circ} \mathrm{C}$. Meanwhile, the VCO solutions were prepared by having the oil at concentrations of $0.1,0.3$, and $0.5 \%(\mathrm{w} / \mathrm{w})$, added with nonionic surfactants of Triton X (0.1$1.0 \% \mathrm{w} / \mathrm{v})$. This mixture was then stirred at $500 \mathrm{rpm}$ until the solution became clear. The solution was stirred again at $500 \mathrm{rpm}$ at $70^{\circ} \mathrm{C}$ for $2 \mathrm{~h}$ to obtain a stable emulsion. The emulsion of GG-VCO was next deposited onto petri dishes $(90 \mathrm{~mm} \times 15 \mathrm{~mm})$ and placed inside Venticell oven at $30^{\circ} \mathrm{C}$ for at least $24 \mathrm{~h}$. GG containing $0.1 \%, 0.3 \%$, and $0.5 \%$ (w/w) of VCO solutions will hereafter be referred to as GG-VCO1, GGVCO3, and GG-VCO5 films, respectively. The positive control used was film of gellan gum, incorporated with norfloxacin, which was prepared by adding $0.01 \%(\mathrm{w} / \mathrm{w})$ of norfloxacin into the stock gellan gum solution. Norfloxacin was used as the positive control in the experiment. All films were preconditioned in a desiccator $\left(24^{\circ} \mathrm{C}, 50 \%\right.$ relative humidity $(\mathrm{RH}))$ for at least 2 days prior to testing.

\subsection{Characterization of the Films}

2.2.1. Ultraviolet Visible Spectroscopy. UV-vis transmission spectra of films were recorded by Varian Cary 50 spectrophotometer at $24^{\circ} \mathrm{C}$ with data interval $=0.5 \mathrm{~nm}$ and scan speed $=$ $300 \mathrm{~nm} / \mathrm{min}$.
2.2.2. Attenuated Total Reflectance. ATR-FTIR spectra were collected using a Perkin Elmer Spectrum 100 FT-IR spectrophotometer with PIKE Miracle ATR accessory (singlebounce beam path, $45^{\circ}$ incident angle, 16 scans, and $4 \mathrm{~cm}^{-1}$ resolution) and all spectra were corrected by the Perkin Elmer Spectrum 100 software.

2.2.3. Mechanical Properties. Stress-strain measurements were obtained using an Instron Universal Testing machine (model 3366) with $\pm 10 \mathrm{kN}$ grips and the cross speed set at $20 \mathrm{~mm} / \mathrm{min}$. Film thickness $(2.0 \mathrm{~cm} \times 6.0 \mathrm{~cm})$ was measured by a hand-held micrometer (Mitutoyo). Young's modulus $(E)$, tensile strength (TS), and toughness ( $T$ ) were calculated from the slope of the linear part of the stress-strain curve and maximum stress and through integration of the area under the curve, respectively. Strain-at-break $(\gamma)$ was also recorded.

2.2.4. Electron Microscopy. Scanning electron microscopy (SEM) images were obtained by using a JOEL JSM 6360 LA electron microscope. SEM images of cross-sections were obtained by freeze-drying the samples in liquid nitrogen $\left(-160^{\circ} \mathrm{C}\right)$. Then, the samples were fractured at $-150^{\circ} \mathrm{C}$, later coated with Auto Fine Coats (JFC-1600), and imaged by SEM.

2.2.5. Swelling. Water uptake was measured by weighing the dried films $\left(W_{\text {dry }}\right)$ prior to immersion into solutions of $\mathrm{pH} 1$, $\mathrm{pH} 7$, and $\mathrm{pH} 12$ in water bath $\left(37 \pm 0.5^{\circ} \mathrm{C}\right)$. The films were removed after $24 \mathrm{~h}$, wiped gently with a tissue to expel surface solution, and then weighed $\left(W_{\text {wet }}\right)$. Water uptake was then determined from the equilibrium-swelling ratio $\left(W_{\text {wet }}-\right.$ $\left.W_{\text {dry }}\right) / W_{\text {dry }}$.

2.2.6. Water Vapor Transmission Rates. The water vapor transmission rates (WVTR) were measured by following a modified ASTM international standard method. The films were fixed on the circular opening of a permeation bottle $(d=$ $1.5 \mathrm{~cm}$ and height $=5.0 \mathrm{~cm}$ ) with an effective transfer area $\left(A=1.33 \mathrm{~cm}^{2}\right)$ and placed in a desiccator $\left(25^{\circ} \mathrm{C}\right.$ and $50 \pm 5 \%$ $\mathrm{RH})$. The WVTR was then determined by the rate of change of mass $(m)$ in these water-filled permeation bottles at $24 \mathrm{~h}$ exposure time of $24 \mathrm{~h}$ using (1) as follows:

$$
\text { WVTR }=\frac{m}{A \Delta t},
$$

where $m / \Delta t$ is water gain per unit time of transfer and $A$ is the area exposed to water transfer $\left(\mathrm{m}^{2}\right)$.

2.2.7. Cell Studies. For the cultivation of normal human skin fibroblast cells (CRL2522-ATCC, USA), the Eagle's minimum essential medium (EMEM, ATCC, USA) supplemented with $10 \%(\mathrm{v} / \mathrm{v})$ fetal bovine serum (FBS, Sigma Aldrich, USA) and $1 \%(\mathrm{v} / \mathrm{v})$ antibiotic (penicillin/streptomycin, Sciencell, USA) were used as the culture medium. Cells were incubated at $37^{\circ} \mathrm{C}$ in a humidified $5 \% \mathrm{CO}_{2}$ atmosphere and subcultured every 3 days as per established protocols and then harvested at $60-80 \%$ confluence.

Film samples were soaked with $70 \%$ alcohol for $5 \mathrm{~min}$ before being placed into 96-well plate (Nunc, Germany), 
which was then sterilized in a biological safety cabinet under UV radiation for $20 \mathrm{~min}$. Prior to cell seeding, the films were soaked into the culture media (EMEM only) for $24 \mathrm{~h}$ and the supernatant was removed before CRL2522 cells (5000 cells/well) were seeded into wells containing the samples and incubated at $37^{\circ} \mathrm{C}$ in a humidified atmosphere of $5 \%$ $\mathrm{CO}_{2}$ for 24,48 , and $72 \mathrm{~h}$. The EMEM culture media without the presence of film samples were used as the negative control in this experiment. The viability of cells in contact with the GG-VCO film samples for $24 \mathrm{~h}, 48 \mathrm{~h}$, and $72 \mathrm{~h}$ of incubation time was examined through a staining procedure of calcein-AM (Life Technologies, USA) and observed by light microscope (Olympus TH4-200) equipped with fluorescence filter (Olympus U-RFL-T UV with blue light excitation). Meanwhile, the normal human skin fibroblast cells' proliferations were quantified by using a CellTiter 96 aqueous one solution assay (Promega, USA) which contained tetrazolium compound [3-(4,5-dimethylthiazol2-yl)-5-(3-carboxy-methoxyphenyl)-2-(4-sulfophenyl)-2Htetrazolium, inner salts; MTS(a)] with electron-coupling reagent (phenazine ethosulfate). Prior to the addition of the assay solution ( $20 \mu \mathrm{L}$ in each wells), the media in all wells that contained film samples, except for the negative control, were replaced with fresh media and later incubated for $3 \mathrm{~h}$. Then, $100 \mu \mathrm{L}$ of the inoculants was transferred into new wells and the absorbance at $490 \mathrm{~nm}$ was measured by using a microplate reader (Multiskan Ascent 96/384, USA). The absorbance readings were converted to cell number using calibration curves of CRL2522 cells in 96-well plates under the same condition.

2.3. Bacterial Studies. Gram-positive (Staphylococcus aureus-S. aureus; Staphylococcus epidermidis-S. epidermidis) and Gram-negative (Pseudomonas aeruginosa-P. aeruginosa; Proteus mirabilis - P. mirabilis) bacteria were used for the antibacterial assay. Mueller-Hinton (MH, Difco, Malaysia) agar was used for the growth of both bacterial types. It was prepared by suspending $38 \mathrm{~g}$ of the $\mathrm{MH}$ powder in $1 \mathrm{~L}$ purified water, heated with frequent agitation, and boiled for $1 \mathrm{~min}$ to completely dissolve the powder. For MH broth, $21 \mathrm{~g}$ of the broth powder was suspended in $1 \mathrm{~L}$ purified water and boiled for $1 \mathrm{~min}$ to dissolve the powder. The prepared agar and broth solutions were autoclaved at $121^{\circ} \mathrm{C}$ for 15 minutes with the final $\mathrm{pH}$ at $7.3 \pm 0.1$. S. aureus and S. epidermidis were grown by direct colony suspension method while $P$. aeruginosa and $P$. mirabilis were grown by growth method. For each isolate, the selected morphologically similar colonies were transferred into $4-5 \mathrm{~mL}$ of $\mathrm{MH}$ broth and mixed using vortex mixer. For the growth method, these two bacterial suspensions were incubated at $37^{\circ} \mathrm{C}$ for 2 to 6 hours. Then, all suspensions were measured by spectrophotometer to obtain an optical density of 1.0 at $600 \mathrm{~nm}$.

In the qualitative studies, agar well diffusion method and disk diffusion method were used for pure VCO and composite films, respectively. For both methods, the inoculum was evenly pipetted on the solid $\mathrm{MH}$ agar and left to dry. $50 \mu \mathrm{L}$ of pure VCO samples was then pipetted into $6 \mathrm{~mm}$ wells on $\mathrm{MH}$ agar plate, while for disk method, the composite films (diameter $\approx 6 \mathrm{~mm}$, three replicates) were placed on the agar. The plates were examined for the presence of zones of growth inhibition after $24 \mathrm{~h}$ of incubation at $37^{\circ} \mathrm{C}$.

In the quantitative antibacterial study, the GG-VCO composite films were incubated in $15 \mathrm{~mL}$ Falcon tube containing $5 \mathrm{~mL} \mathrm{MH}$ broth and bacterial suspension for $2 \mathrm{~h}$ at $37^{\circ} \mathrm{C} .10 \mu \mathrm{L}$ of the inoculums was taken at intervals of 0 and $2 \mathrm{~h}$. The viable population of the bacteria was enumerated by a sequentially diluted $100 \mu \mathrm{L}$ solution that contained $10 \mu \mathrm{L}$ inoculum and $90 \mu \mathrm{L}$ phosphate-buffered saline (PBS) in 96-well plates to obtain serial dilution of $10^{1}-10^{8}$ colony-forming units (CFU) per $\mathrm{mL}$. Then, $20 \mu \mathrm{L}$ of each dilution series was aseptically plated in triplicate on $\mathrm{MH}$ agar plates and later incubated for $24 \mathrm{~h}$ at $37^{\circ} \mathrm{C}$. Agar plates coated with bacteria suspension served as the negative control for bacterial growth. Colonies appearing on all $\mathrm{MH}$ agar plates after $24 \mathrm{~h}$ of incubation at $37^{\circ} \mathrm{C}$ were counted and reported as the viable population in CFU per $\mathrm{mL}$.

\section{Results and Discussion}

3.1. Physical Appearance. In general, gellan gum (GG) solution is immiscible with virgin coconut oil due to its high interfacial tension that is typical for oils with most polymers. In this study, a surfactant, that is, Triton X-102, was introduced into the mixture of gellan gum and virgin coconut oil (VCO) to reduce the interfacial tension above their critical micelle concentration (CMC). Below the CMC point $(<1 \% \mathrm{w} / \mathrm{v})$, the phase separation was observed (Figure 1(a)). This might be because of fewer molecules of VCO as a nonpolar substance solubilized in GG solution. The GG-VCO composite films were successfully prepared by the addition of $\approx 1 \%(\mathrm{w} / \mathrm{v})$ Tritox X-102 (Figure 1(b)). At this particular concentration, the surfactant formed sufficient micelles, which were then capable of solubilizing the nonpolar substances of VCO, thus interacting with GG. All the prepared GG-VCO films with Triton X-102 were transparent, with identical transmittances around $\approx 95 \%(\lambda=700 \mathrm{~nm})$, which were similar to freestanding GG film (Figure 1(c)).

3.2. UV-Vis and ATR Spectroscopy. UV-visible absorbance of GG and GG-VCO films is shown in Figure 2(a). GG shows an absorption peak at $\lambda=260 \mathrm{~nm}$ corresponding to glucuronic acid of gellan gum [12]. The inclusion of VCO in GG exhibited two characteristics of absorbance bands at $\lambda=$ $230 \mathrm{~nm}$ and $\lambda=275 \mathrm{~nm}$ which refer to conjugated dienes and conjugated trienes, respectively, which are commonly present in vegetable oils [13]. The absorption of glucuronic acid present as a shoulder aside from conjugated trienes in the GG-VCO films may prove the existence of both materials in the composite films.

ATR spectra of the GG-VCO films further confirm the presence of characteristic peaks of both materials. VCO has 6 prominent peaks dominated by its fats and oils content (Figure 2(b)). The peaks at 2926 and $2857 \mathrm{~cm}^{-1}$ relate to the saturated alkyl and the carbonyl groups of the fatty acids, respectively. Other peaks appearing at 1742, 1464, 1377, and $1112 \mathrm{~cm}^{-1}$ were from the stretching of carboxylic $(\mathrm{C}=\mathrm{O})$, 


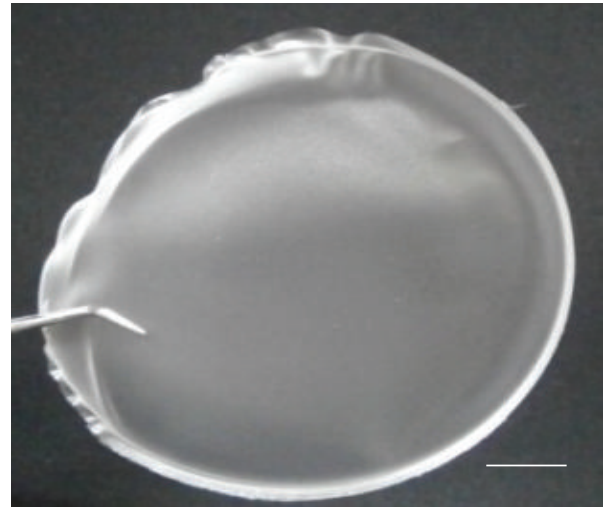

(a)

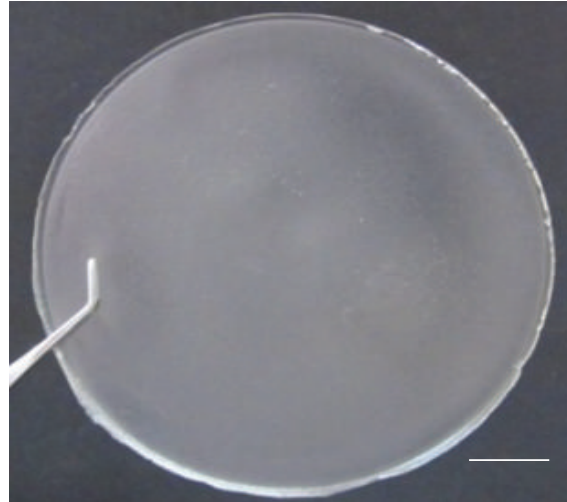

(b)

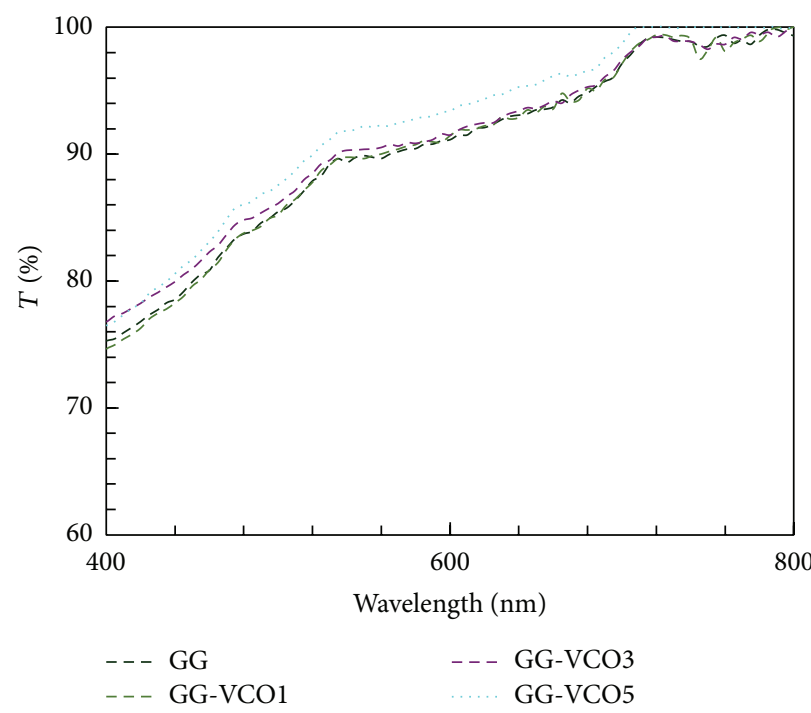

(c)

Figure 1: Photograph of gellan gum-virgin coconut oil film with (a) $0.5 \%(\mathrm{w} / \mathrm{v})$ and (b) $1.0 \%$ (w/v) of Triton X-102 and (c) transmittance of pure GG film and GG-VCO composite films with 1.0\% (w/v) Triton X-102. Scale bar represents $2 \mathrm{~cm}$.

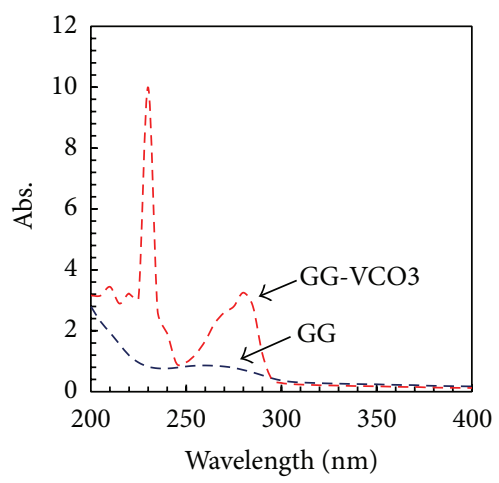

(a)

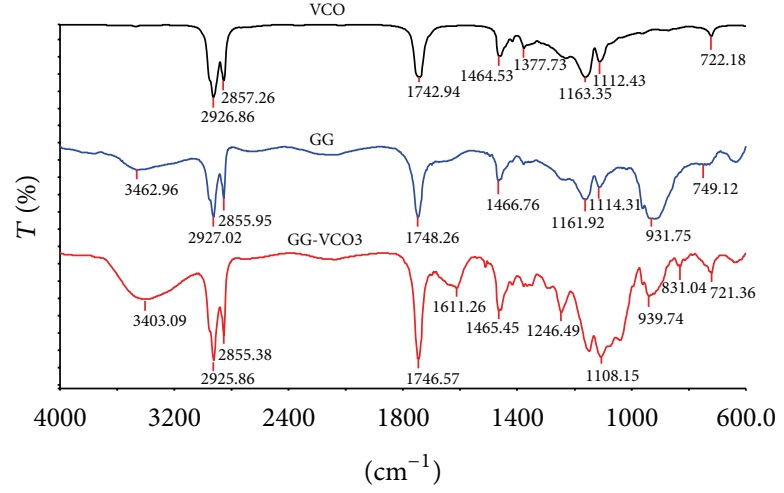

(b)

FIGURE 2: (a) UV-visible absorbance of pure GG and GG-VCO3 films and (b) ATR spectra of VCO, pure GG film, and GG-VCO3 film. 
TABLE 1: Summary of the tensile strength (TS), Young's modulus (YM), toughness (T), strain-at-break $(\gamma)$, water vapor transmission rates (WVTR), and swelling in buffer solutions of gellan gum-virgin coconut oil composite films.

\begin{tabular}{|c|c|c|c|c|c|c|c|c|c|}
\hline \multirow{2}{*}{ Sample } & \multirow{2}{*}{ Thick $(\mu \mathrm{m})$} & \multirow{2}{*}{$\mathrm{TS}(\mathrm{MPa})$} & \multirow{2}{*}{$\mathrm{YM}(\mathrm{MPa})$} & \multirow{2}{*}{$T\left(\mathrm{Jg}^{-1}\right)$} & \multirow{2}{*}{$\gamma(\%)$} & \multirow{2}{*}{ WVTR $\left(\mathrm{g} \mathrm{m}^{-2} \mathrm{~d}^{-1}\right)$} & \multicolumn{3}{|c|}{ Swelling (\%) } \\
\hline & & & & & & & $\mathrm{pH} 1$ & $\mathrm{pH} 7$ & pH 12 \\
\hline$\overline{G G}$ & $30 \pm 10$ & $80 \pm 12$ & $4600 \pm 330$ & $0.26 \pm 0.39$ & $2 \pm 1$ & $422 \pm 113$ & $308 \pm 15$ & $987 \pm 113$ & $724 \pm 11$ \\
\hline GG-VCO1 & $70 \pm 10$ & $18 \pm 1$ & $473 \pm 66$ & $0.50 \pm 0.01$ & $6 \pm 1$ & $364 \pm 22$ & $109 \pm 13$ & $394 \pm 22$ & $265 \pm 24$ \\
\hline GG-VCO3 & $80 \pm 6$ & $14 \pm 2$ & $130 \pm 19$ & $0.67 \pm 0.33$ & $13 \pm 2$ & $271 \pm 29$ & $71 \pm 2$ & $263 \pm 15$ & $200 \pm 15$ \\
\hline GG-VCO5 & $110 \pm 17$ & $8 \pm 1$ & $67 \pm 2$ & $0.38 \pm 0.06$ & $14 \pm 1$ & $250 \pm 32$ & $48 \pm 3$ & $181 \pm 12$ & $142 \pm 4$ \\
\hline
\end{tabular}

bending of methylene $\left(\mathrm{CH}_{2}\right)$, bending of methyl $\left(\mathrm{CH}_{3}\right)$, and stretching of esters $(\mathrm{C}-\mathrm{O})$, respectively [14]. Meanwhile, the gellan gum film exhibits two prominent transmittance bands at 3462 and $931 \mathrm{~cm}^{-1}$, none of which appears in pure VCO. The signal in the region $3000-3500 \mathrm{~cm}^{-1}$ is typical due to stretching of $\mathrm{O}-\mathrm{H}$ group and a band appearing at $931 \mathrm{~cm}^{-1}$ is due to bending of glycosidic link in gellan gum [15]. Combining VCO into GG resulted in these two being observed in the GG-VCO films at 3403 and $939 \mathrm{~cm}^{-1}$, confirming the interaction of the blends. A new distinctive peak, which is not distinct in either VCO or GG, was also observed at $1611 \mathrm{~cm}^{-1}$ and correlates to $\mathrm{C}=\mathrm{C}$ stretching within the aromatic ring, representing the existence of phenolic compounds in VCO [16]. The stretching alkyl signal in VCO at $2926 \mathrm{~cm}^{-1}$ and $2927 \mathrm{~cm}^{-1}$ in GG shifted to $2925 \mathrm{~cm}^{-1}$ in GG-VCO films ratifying the hydrogen bonding interaction in GG-VCO blends [17]. The bonding mainly resulted from the $-\mathrm{COO}^{-}$of carboxyl groups and $-\mathrm{OH}$ and $-\mathrm{COCH}_{3}$ groups in VCO, respectively. There was also a significant change of enlargement peak of GG-VCO film, particularly at $1246 \mathrm{~cm}^{-1}$ and $1108 \mathrm{~cm}^{-1}$, due to an increased stretching vibration of esters group of gellan gum and VCO [14]. All prominent peaks of VCO were recorded in GG-VCO films, with significant changes in variation/shifting of transmittance intensities, for example, at $1746 \mathrm{~cm}^{-1}\left(v_{\mathrm{G}=0}\right)$, further indicating that GG and VCO could interact to produce a stable network composite film.

3.3. Mechanical Characteristics and Microscopy. Free-standing gellan gum (GG) film is brittle and almost impossible to use in pharmaceutical applications as a wound dressing material. To elucidate this behavior, virgin coconut oil, which acts as a plasticizer, has been unified into GG film. The inclusion of virgin coconut oil (VCO) into GG caused the films to become robust and flexible due to the decrease in tensile strength (TS) and Young's modulus $(E)$, but it increased the toughness $(T)$ and strain-at-break $(\gamma)$ values (Figure 3 and Table 1). The TS and E of GG-VCO1 film decreased about 4 -fold (from $80 \pm 12 \mathrm{MPa}$ to $18 \pm 1 \mathrm{MPa}$ ) and 10 -fold (from $4600 \pm 330 \mathrm{MPa}$ to $473 \pm 66 \mathrm{MPa}$ ), respectively. In contrast, the $T$ and $\gamma$ increased about 2-fold (from $0.26 \pm$ $0.39 \mathrm{Jg}^{-1}$ to $0.50 \pm 0.01 \mathrm{~J} \mathrm{~g}^{-1}$ ) and 3 -fold (from $2 \pm 1 \%$ to $6 \pm 1 \%$ ) correspondingly upon the addition of $0.1 \%(\mathrm{w} / \mathrm{w})$ VCO. The inclusion of larger amount of VCO (up to $0.5 \% \mathrm{w} / \mathrm{w}$ ) further decreased the TS and $E$ but increased the $T$ and $\gamma$ values (Table 1).

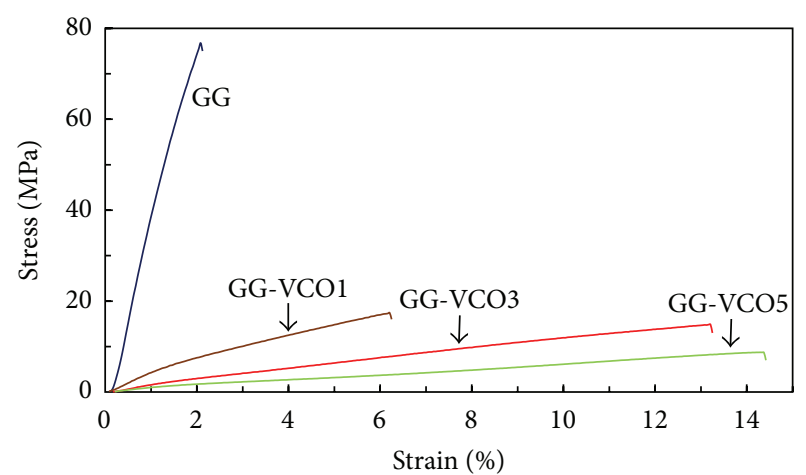

FIGURE 3: Typical stress-strain curves of GG and GG-VCO films at different concentrations.

The mechanism of formation involved in GG film is closely related to the conformational transition from coil to helix structure. In aqueous solution at high temperatures $\left(\sim 60^{\circ} \mathrm{C}\right)$, gellan gum chains are in a disordered single coil state. Upon cooling from 70 to $30^{\circ} \mathrm{C}$ [18], the gellan solution promotes the formation of double helices stabilized by internal hydrogen bonding [19]. This facilitates the tight packing of GG chains, resulting in brittle film. However, the addition of VCO, composed mainly of lauric acid (C12 78\%) at the sn-2 position [20], which contains hydroxyl groups are responsible to promote the formation of hydrogen bonds between GGVCO. This bonding replaces the hydrogen bonds between GG-GG chains and thus decreases the intermolecular forces along polymer chains, reducing its strength and improve the strain-at-break of the composite film [21].

Another factor contributing to the improving flexibility of the GG-VCO film is the emulsion polymerization process as revealed by scanning electron microscopy (Figure 4). Clear trace of micelles due to emulsification of VCO monomers was observed in the cross-section of GG-VCO1 film (Figure 4(b)). The appearances of these micelles were heightened in GGVCO3 and GG-VCO5 films (Figures 4(c) and 4(d)). The trap of emulsification inside the micelles is understood during conformational transition of gellan gum from coil-to-helix structure. At $70^{\circ} \mathrm{C}$ or right after the mixing process of GGVCO with Triton X-102 (1\% w/w), the dispersions have a huge number of micelles and quick drying $(\leq 10 \mathrm{~min})$ manners of gellan gum to $30^{\circ} \mathrm{C}$ leave no chance for the emulsion to settle off. The micelles were then stuck in the GG-VCO matrix, causing the GG film to restrain the strain in tensile testing and thus improving the $T$ and $\gamma$ of GG-VCO films. In contrast, this 


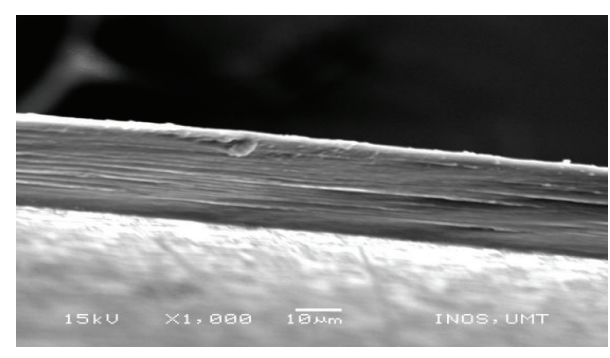

(a)

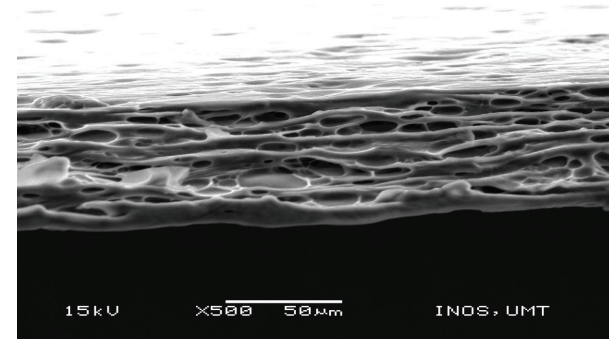

(c)

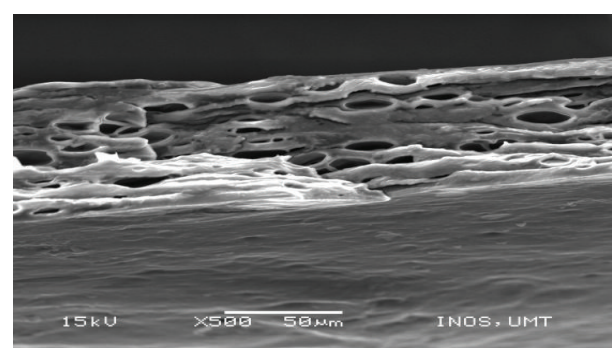

(b)

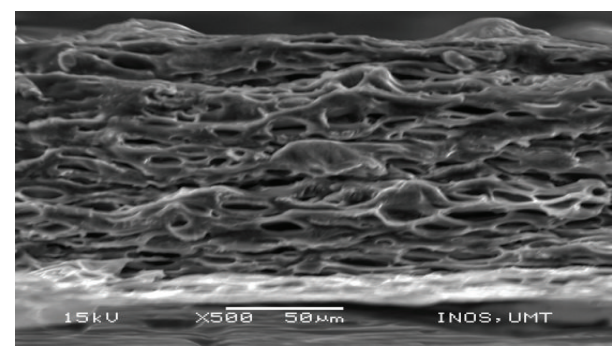

(d)

FIGURE 4: Scanning electron microscopy images of cross-sectional area of (a) pure GG film, (b) GG-VCO1 film, (c) GG-VCO3 film, and (d) GG-VCO5 films.

leads to less interaction between GG chains and consequently decreases in TS and $E$.

3.4. Swelling and Water Vapor Transmission Rates. The swelling degree of GG-VCO films in buffer solutions is summarized in Table 1. It is well known that GG is absorbed to a lesser extent in acidic $\mathrm{pH}$. The carboxylic group of L-ascorbic acid becomes protonated to $\mathrm{COOH}$ in this environment and turns the materials less soluble ( 308 $\pm 15 \%)$ [22]. In contrast, at basic $\mathrm{pH}$, the residue of $\mathrm{D}$-glucuronic acid of carboxylic groups is in the anionic form, $\mathrm{COO}^{-}$, and therefore becomes more soluble in the solution ( $724 \pm 11 \%)$. However, at intermediate $\mathrm{pH} \sim 7.4$, the number of ionic groups is highest in the buffer solution, resulting in maximum water uptake rates ( 987 $\pm 113 \%)$. GG-VCO films also showed noticeable increase of water resistance in all $\mathrm{pH}$ conditions and the values heightened at higher VCO concentrations. For example, GG-VCO1 film absorbs only $109 \pm 13 \%$ in $\mathrm{pH} 1$, $394 \pm 22 \%$ in $\mathrm{pH} 7$, and $265 \pm 24 \%$ in $\mathrm{pH} 12$, and the rates absorbed are lesser for GG-VCO3 and GG-VCO5 films. This might be caused either by the hydrogen bonds occurring in GG-VCO films, as proved in ATR spectroscopy, which limits the availability of free-hydroxyl groups to bind to water molecules, or due to hydrophobicity property of VCO itself. The higher the amount of VCO, the higher water resistance of the film expected.

The water vapor transmission rates (WVTRs) values of control and GG-VCO films are in the range of 250$422 \mathrm{~g} \mathrm{~m}^{-2} \mathrm{~d}^{-1}$ (Table 1). The values decreased upon addition of VCO which can be expected due to tight packing of VCO micelles in GG matrix (see Figures 4(c) and 4(d)), which then interrupt water vapor diffusion rates. However, these values still remain within the range of WVTR values (90$2,893 \mathrm{~g} \mathrm{~m}^{-2} \mathrm{~d}^{-1}$ ) as reported for eight commercially available synthetic wound dressings [23].

3.5. Thermal Analysis. TGA and DSC thermograms of pure GG and GG-VCO composite films are presented in Figure 5. The degradation below $\left(T \leq 100^{\circ} \mathrm{C}\right)$ which occurred for pure GG films is common due to evaporation of the moisture content in the films (Figure 5(a)) [24, 25]. The degradation of pure GG film started approximately at temperature onset $\left(T_{o}\right) \approx 246^{\circ} \mathrm{C}$ and the temperature completion $\left(T_{c}\right)$ at $570^{\circ} \mathrm{C}$ (Table 2). Addition of VCO into GG film decreased the $T_{o}$ values $\left(234^{\circ} \mathrm{C}-240^{\circ} \mathrm{C}\right)$ but increased the $T_{c}$ values depending on the concentration of VCO (Table 2). For example, the $T_{c}$ of GG-VCO1 film recorded at $T=586^{\circ} \mathrm{C}$, whereas GGVCO5 film at $T=622^{\circ} \mathrm{C}$, with an increment of $16^{\circ} \mathrm{C}$ and $52^{\circ} \mathrm{C}$, respectively than pure GG films at $T=570^{\circ} \mathrm{C}$. This shows that the addition of VCO exhibits better outcome in increasing thermal stability of composite films due to certain degree of interaction between GG and VCO as demonstrated by ATR spectroscopy.

The degradation of composite films recorded in TGA thermogram nicely corresponds with the changes that occurred in DSC thermograms. An exothermic peak observed in DSC thermogram for pure GG film at $T=100^{\circ} \mathrm{C}$ was due to the loss of water molecules which might be encapsulated during drying process (Figure 5(b)). However, this peak did not appear in all GG-VCO films, showing that lesser free-hydroxyl groups are available in the blends. The glass transition of GG film and GG-VCO composite films is recorded at lower temperature $\left(\leq 100^{\circ} \mathrm{C}\right)$ (Table 2$)$ which indicates that the samples are amorphous as a result of the film casting preparation [26]. The melting point $\left(T_{m}\right)$ 


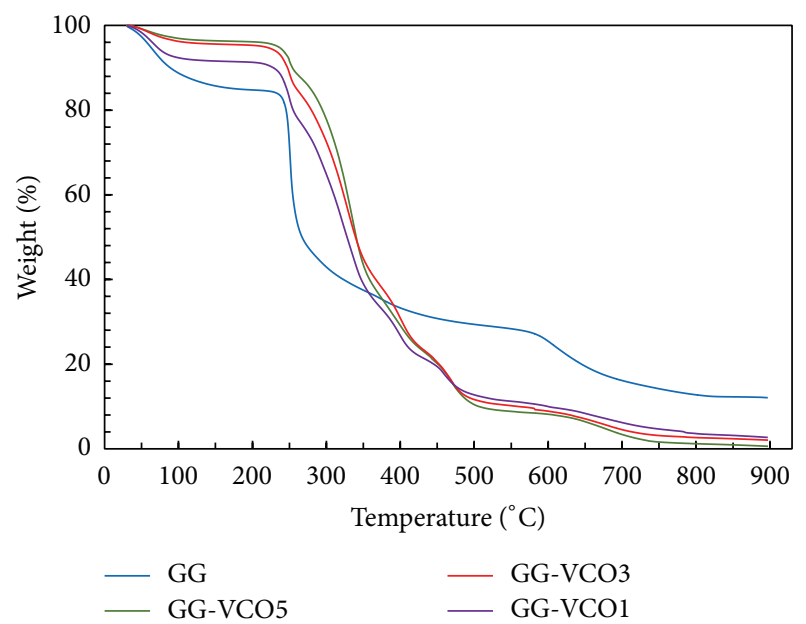

(a)

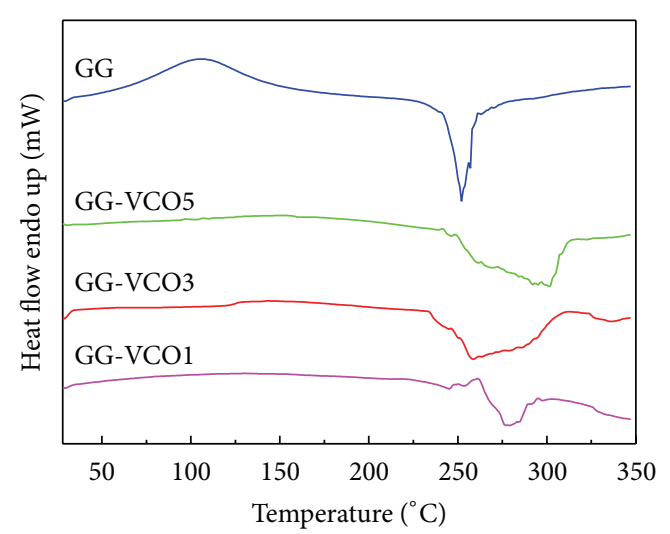

(b)

FIGURE 5: (a) Thermogravimetric thermograms and (b) differential scanning calorimetry thermograms of pure GG and GG incorporated with virgin coconut oil at different concentrations.

TABLE 2: Thermal gravimetry and differential scanning calorimetry properties of GG and GG-VCO composite films.

\begin{tabular}{lccccccc}
\hline \multirow{2}{*}{ Sample } & \multicolumn{2}{c}{$\mathrm{TGA}\left({ }^{\circ} \mathrm{C}\right)$} & \multicolumn{3}{c}{$\mathrm{DSC}\left({ }^{\circ} \mathrm{C}\right)$} \\
& $T_{o}$ & $T_{c}$ & $T_{g}$ & $T_{o}$ & $T_{m}$ & $T_{c}$ \\
\hline GG & 246 & 570 & 74 & 243 & 248 & 252 & $T_{c}-T_{o}$ \\
GG-VCO1 & 234 & 586 & 53 & 271 & 276 & 281 & 10 \\
GG-VCO3 & 236 & 578 & 32 & 260 & 269 & 277 \\
GG-VCO5 & 240 & 622 & 91 & 260 & 270 & 281 \\
\hline
\end{tabular}

$T_{o}=$ onset, $T_{c}=$ completion, $T_{g}=$ glass transition, and $T_{m}=$ melt temperature of the melt films.

values of the GG-VCO composite films increased compared to pure GG films. Not limited to that, broad endothermic peaks appeared for GG-VCO composite films with increased range $\left(T_{c}-T_{o}\right)$ of temperature onset $\left(T_{o}\right)$ and temperature completion $\left(T_{c}\right)$ showing that the incorporation of VCO has increased the crystallization of the sample and improved the thermal behavior of the composite films [27].

3.6. Cell Studies. For the cell studies, GG-VCO3 composite films were adapted to be examined, due to optimum toughness offered by the sample (toughness, $T \approx 0.67 \pm 0.33 \mathrm{~J} \mathrm{~g}^{-1}$ ) compared to its counterpart (Table 1). Adequate toughness and flexibility are important in developing the dressing materials to allow confirmation to uneven body surface. The cell viability and proliferation of GG-VCO3 film on human skin fibroblast cells (CRL2522) are shown in Figure 6. The cell growth on control, tissue culture polystyrene plate (TCPP), and GG was extremely healthy with their morphology changed to elongated/spindle-like shape after incubation for $72 \mathrm{~h}$ (Figures 6(a) and 6(b)). However, a limited number of CRL2522 cells were observed on the GG-VCO3 composite film with half of them being morphologically changed to spindle-like shape and the other half in rounded shape (Figure 6(c)). Even though the cell viability on the GG-VCO3 film is low compared to GG film, it shows that the VCO is unlikely to be cytotoxic.
The cell viability observed was parallel with the proliferation result quantified by using CellTiter 96 aqueous one solution assay on the samples. Because a limited number of CRL2522 cells were observed on the GG-VCO3 films, the cell proliferation was recorded at $\approx 1,450$ cells/well after incubation for $24 \mathrm{~h}$ (Figure 6(d)). The number does not change much even after $72 \mathrm{~h}$ of incubation on GG-VCO3 film which was recorded at $\approx 1,650$ cells/well, an increment of $14 \%$. On free-standing GG film, the cell proliferation multiplied to 72,000 cells/well after incubation for $72 \mathrm{~h}$, with an increment of nearly $\approx 450 \%$ or 5 -fold compared to incubation for $24 \mathrm{~h}$ at 13,600 cells/well. The same cell proliferation number was observed on TCPP as a negative control that increased to 80,000 cells/well after incubation for $72 \mathrm{~h}$.

The low number of CRL2522 cells attached (proved from cell viability and proliferation results) on the GG-VCO3 films could be due to the influence of physics-chemistry properties such as surface roughness, hardness, hydrophobicity, and hydrophilicity of the materials [28-31]. The use of VCO which is an oily surface (hydrophobic surface) in the GG film possibly hardens the adherence of CRL2522 cells on the composite film. The trace of micelles on the surface of composite films due to emulsion polymerization process (refer to Figure 4) could be another factor which distorted the cell growth. Further study is needed to understand low growth factor on this type of composite materials. 


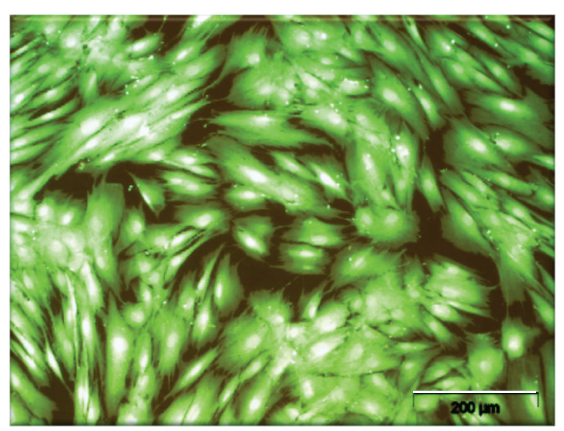

(a)

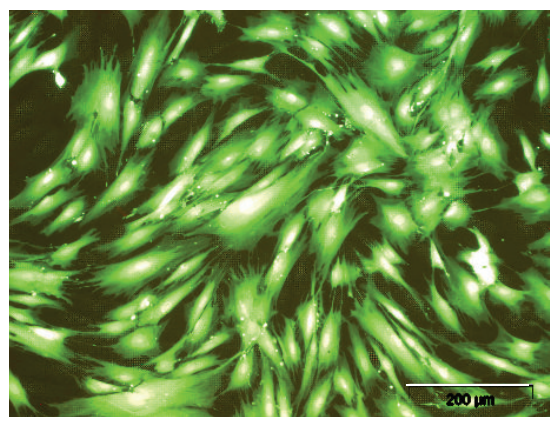

(b)

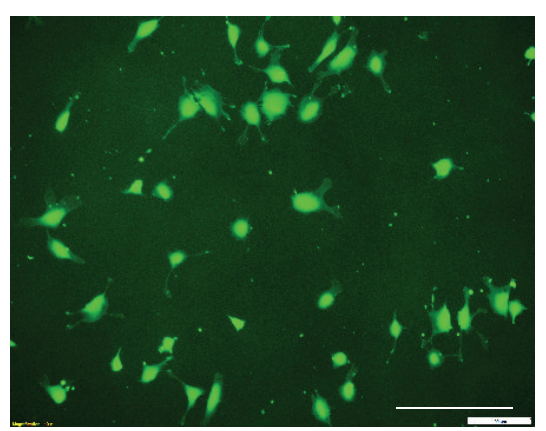

(c)

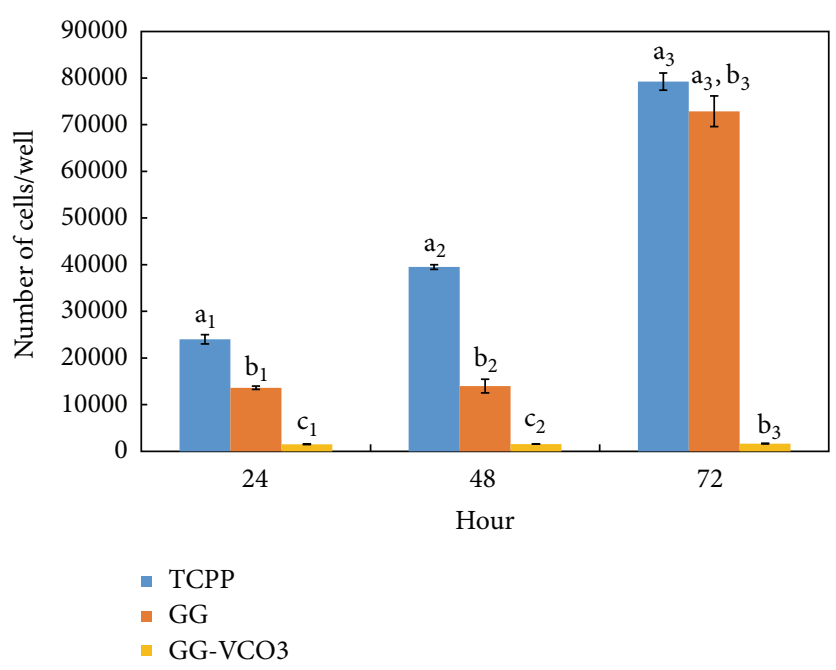

(d)

FIGURE 6: (a-c) Fluorescence microscope images of the cell viability on the (a) tissue culture polystyrene plate, TCPP, (b) gellan gum (GG) film, (c) gellan gum film with $0.3 \%$ (w/w) virgin coconut oil (GG-VCO3) film, and (d) cell proliferation of GG and GG-VCO3 films cultured in the medium containing human skin fibroblast cells (CRL2522) for $72 \mathrm{~h}$. Error bars indicated standard deviation $(n=3)$. Statistical analysis using one way ANOVA followed by post hoc test shown by different letters was statistically different $(P \leq 0.05)$. Scale bars represent $200 \mu \mathrm{m}$.

3.7. Antibacterial Activity. Antibacterial activities of GGVCO composite films were studied through qualitative and in vitro quantitative methods against four species of bacteria, that is, two Gram-positive bacteria (Staphylococcus aureusS. aureus; Staphylococcus epidermidis-S. epidermidis) and two Gram-negative bacteria (Pseudomonas aeruginosa-P. aeruginosa; Proteus mirabilis - $P$. mirabilis). A qualitative study was conducted using agar well diffusion and disc diffusion method. Meanwhile, viable cell count method was performed for examining the antibacterial activities quantitatively.

In the qualitative studies conducted by agar well diffusion method, pure VCO solutions demonstrated no sign of inhibition zones against the four species of bacteria, that is, S. aureus and S. epidermidis (Gram-positive) and $P$. aeruginosa and $P$. mirabilis (Gram-negative) (Figures 7(a)$7(d))$. The same observation on agar well diffusion method which no inhibition zones on $\mathrm{MH}$ agar plates were found on the GG-VCO1, GG-VCO3, and GG-VCO5 composite films assessed through disc diffusion method (Figures $7(\mathrm{e})-7(\mathrm{~h})$ ). The inhibition zones were only observed on positive control disc, that is, GG film containing $0.01 \%(w / w)$ of norfloxacin
(GG-NF) as summarized in Table 3. S. epidermidis shows the most susceptible to the GG-NF at $24.6 \pm 0.6 \mathrm{~mm}$, followed by $S$. aureus at $16.3 \pm 1.5 \mathrm{~mm}, P$. aeruginosa at $13.3 \pm 0.6 \mathrm{~mm}$ and $P$. mirabilis recorded the most resistance to this antibiotic at $9.0 \pm 0.1 \mathrm{~mm}$. No inhibition zone was observed on pure VCO solution which could be due to complexity of VCO chemical compositions and its huge molecular size to diffuse into the agar. For disk method, the negative observation of GG-VCO films against all four bacteria might be due to the fact that lesser degree of VCO has contact with MH agar, which reduces the chances of the latter to diffuse into the agar.

In order to investigate the antibacterial effect of VCO further, the in vitro quantitative test was examined. Based on the results shown in Figure 8, GG-NF films demonstrated a solid decrease of bacteria cells in all inoculums after $2 \mathrm{~h}$ of incubation. Similar trend to disc diffusion method results observed for GG-NF films which S. epidermidis shows the most susceptible while $P$. mirabilis recorded the most resistance to the norfloxacin antibiotic.

It is widely known that norfloxacin is active in vitro against Gram-positive cocci, Pseudomonadaceae, and also Enterobacteriaceae. S. aureus and S. epidermidis belong to 
TABLE 3: Disc diffusion test results of gellan-norfloxacin (GG-NF), gellan gum (GG), and gellan gum containing different concentrations of virgin coconut oil composite films (GG-VCO1, GG-VCO3, and GG-VCO5) against the four tested bacteria as indicated by the zone of inhibition ( $\mathrm{mm})$.

\begin{tabular}{|c|c|c|c|c|c|}
\hline \multirow{3}{*}{ Bacteria species } & \multicolumn{5}{|c|}{ Zone of inhibition $(\mathrm{mm})^{1,2}$} \\
\hline & \multicolumn{3}{|c|}{ Control } & \multicolumn{2}{|c|}{ GG-VCO samples } \\
\hline & GG-NF & GG & GG-VCO1 & GG-VCO3 & GG-VCO5 \\
\hline S. aureus & $16.3 \pm 1.5^{\mathrm{a}}$ & NI & NI & NI & NI \\
\hline S. epidermidis & $24.6 \pm 0.6^{\mathrm{b}}$ & $\mathrm{NI}$ & NI & NI & NI \\
\hline P. aeruginosa & $13.3 \pm 0.6^{\mathrm{c}}$ & NI & NI & NI & NI \\
\hline P. mirabilis & $9.0 \pm 0.0^{\mathrm{d}}$ & NI & NI & NI & NI \\
\hline
\end{tabular}

${ }^{*} \mathrm{NI}$ indicated no inhibition zones were recorded.

${ }^{1}$ Values correspond to mean \pm standard deviation.

${ }^{2 \mathrm{a}-\mathrm{d}}$ Different letters in columns are significantly different $(P \leq 0.05)$.

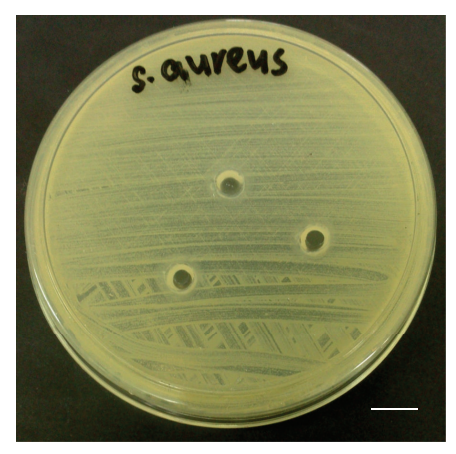

(a)

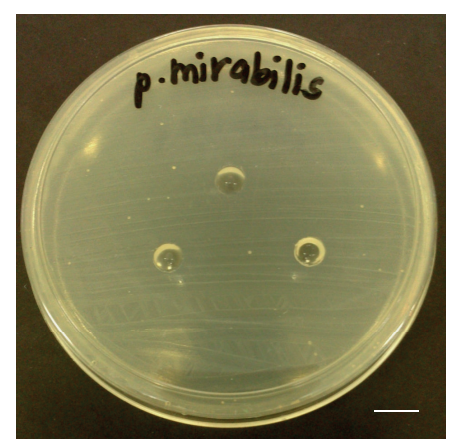

(d)

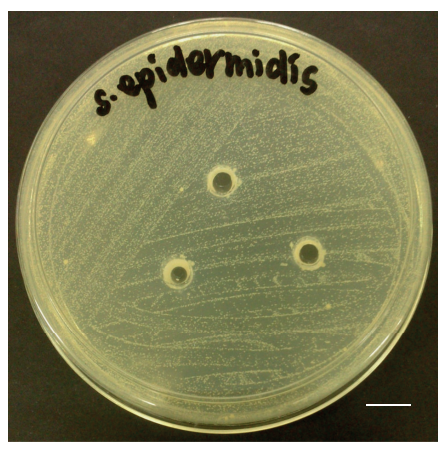

(b)

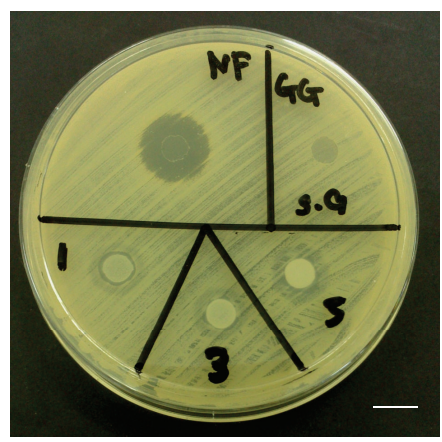

(e)

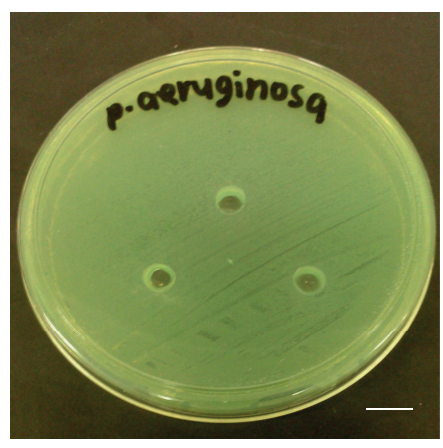

(c)

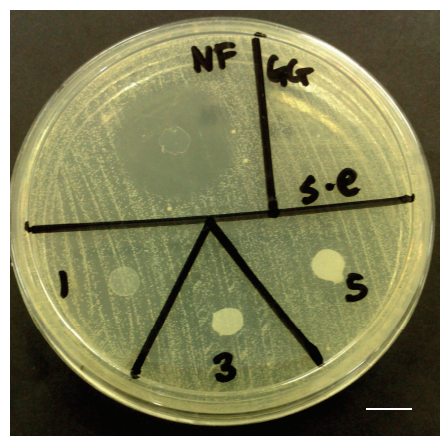

(f)

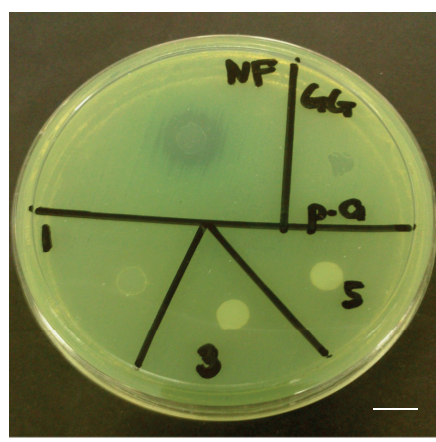

(g)

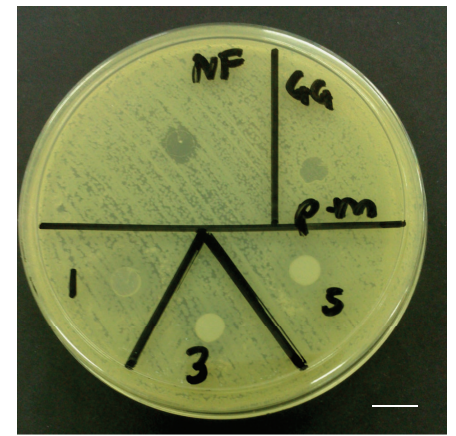

(h)

Figure 7: (a-d) Agar well diffusion test results of pure VCO sample against (a) S. aureus, (b) S. epidermidis, (c) P. aeruginosa, and (d) P. mirabilis; (e-h) disk diffusion test results of GG-VCO films against (e) S. aureus, (f) S. epidermidis, (g) P. aeruginosa, and (h) P. mirabilis. GG, $\mathrm{NF}, 1,3$, and 5 labelled on the plates indicated gellan gum (negative control), GG-NF (positive control), GG-VCO1, GG-VCO3, and GG-VCO5 films, respectively. Scale bar represents $1 \mathrm{~cm}$. 


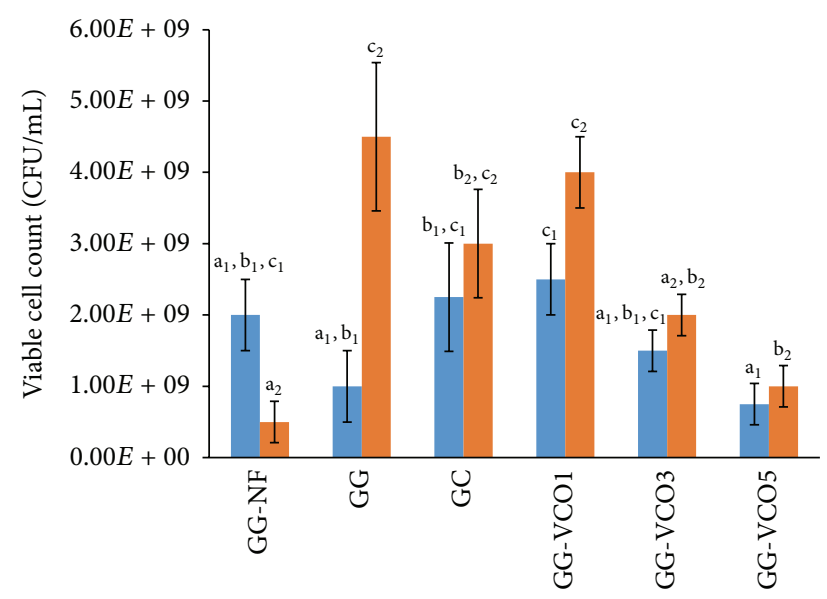

(a)

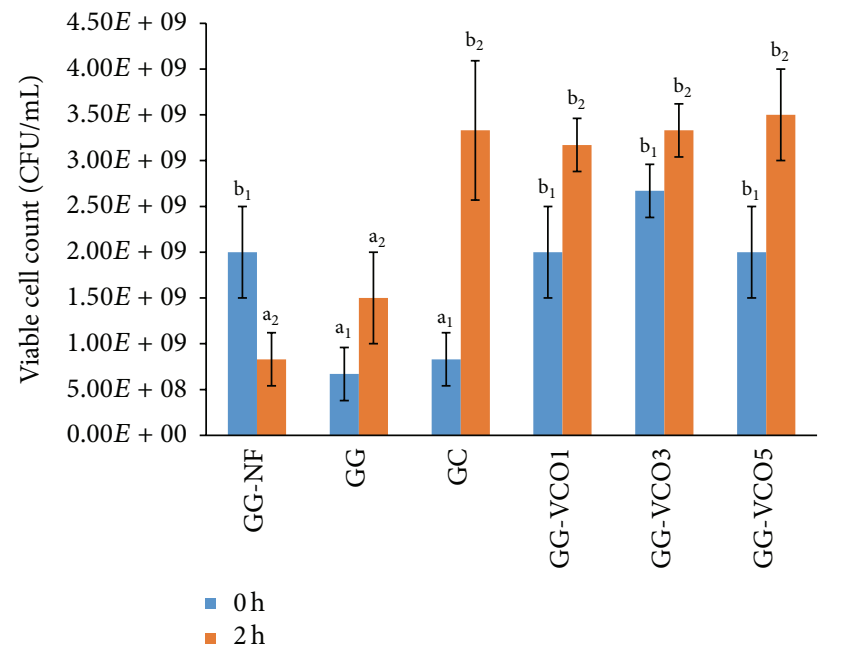

(c)

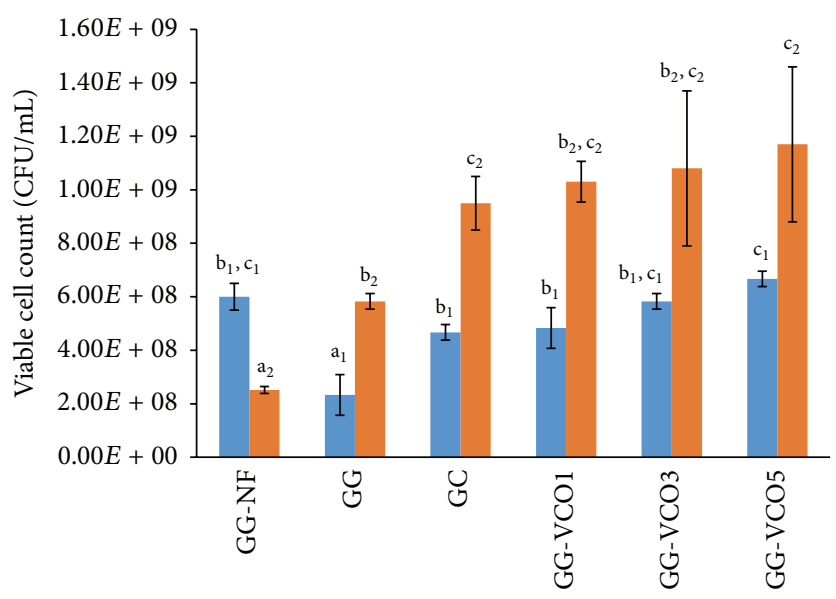

(b)

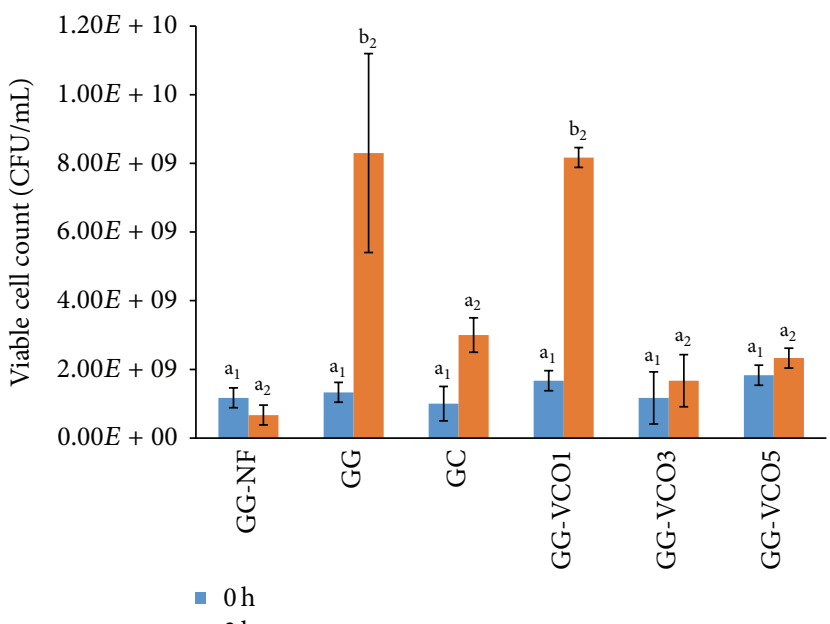

(d)

Figure 8: Viable cell count of Gram-positive bacteria (a) S. aureus and (b) S. epidermidis and Gram-negative bacteria (c) P. aeruginosa and (d) P. mirabilis as expressed in the colony-forming units $(\mathrm{CFU} / \mathrm{mL})$ after $2 \mathrm{~h}$. " $0 \mathrm{~h}$ " indicated the number of colonies in the inoculum. GGNF, GG, GC, GG-VCO1, GG-VCO3, and GG-VCO5 indicated gellan gum with $0.01 \% \mathrm{w} / \mathrm{w}$ norfloxacin (positive control), gellan gum (negative control), growth control, and gellan gum containing $\mathrm{VCO}$ at $0.1 \%, 0.3 \%$, and $0.5 \%(\mathrm{w} / \mathrm{w})$, respectively. Error bars indicated standard deviation $(n=3)$. Statistical analysis using one way ANOVA followed by post hoc test shown by different letters was statistically different $(P \leq 0.05)$.

Gram-positive cocci, $P$. aeruginosa is in the family of Pseudomonadaceae, and P. mirabilis is under the group of Enterobacteriaceae [32]. There was no reduction of bacteria colonies in the inoculum that have been immersed with GG, GG-VCO1, GG-VCO3, and GG-VCO5 films after $2 \mathrm{~h}$ against all four bacteria tested, that is, S. aureus, S. epidermidis, $P$. aeruginosa, and $P$. mirabilis (Figure 8 ).

The quantitative results of the assay showed that VCO does not possess strong antibacterial property on its own. Previously, it has been hypothesized that the bactericidal effect of VCO is induced by its free fatty acids, particularly lauric acid (C12) and small extent of capric acid (C10) and caprylic acid (C8) [11]. VCO must be metabolized to release those components and exert its antimicrobial effects [33]. Another mechanism proposed for the antibacterial effects of VCO is the lipolyzation process with lipase and water to form monoglyceride, for which the structure consists of glyceride molecule attached to either the sn- 1 or sn-2 position of the glycerol $[34,35]$. The derivative of monoglyceride, known as monolaurin or monoester of the lauric acid, is the most effective in inhibiting the microorganism by disrupting the cell membrane and the cytoplasm of cells [11]. The content of monolaurin is dependent on the concentration of VCO. Higher contents of VCO may have higher content of monoglyceride to transform to monolaurin derivative and thus exert the antimicrobial effects. This assumption is supported by a study conducted by Altiok and coworkers in their research, which examined the antibacterial properties of chitosan film with thyme oil [36]. In their study, chitosan film with thyme oil at concentrations of $0.2 \%, 0.4 \%$, and $0.6 \%(\mathrm{v} / \mathrm{v})$ showed no inhibition zones on all 4 bacteria, namely, Escherichia coli, Klebsiella pneumoniae, Pseudomonas 
aeruginosa, and Staphylococcus aureus. However, inhibition zones were observed on the chitosan film with higher concentrations of thyme oil ranging from $0.8 \%$ to $1.2 \%(\mathrm{v} / \mathrm{v})$ with clear zones recorded at $15.5-19 \mathrm{~mm}$ [36]. The authors proposed the killing of the bacteria at higher concentrations of thyme oil is due to the hydrophobic effect of phenolic groups, namely, carvacrol and thymol, which cause deterioration of the bacteria membrane; thus, the bacteria died [37]. Further study should be carried out to understand the effect of VCO at high concentrations against microorganism in gellan gum materials.

\section{Conclusion}

This study successfully prepared gellan gum (GG) films incorporated with virgin coconut oil (VCO). The evaluation of the mechanical properties showed that inclusion of VCO into GG membrane improved the strain-at-break at a cost of reducing the tensile strength and Young's modulus. The swelling of GG-VCO films decreased in all $\mathrm{pH}$ buffers $(\mathrm{pH}$ $1, \mathrm{pH} \mathrm{7}$, and $\mathrm{pH} 12$ ), whereas thermal behavior values increased upon the addition of higher contents of VCO. The water vapor transmission rates of GG-VCO films were comparable to commercially available wound dressing in the range of $250-422 \mathrm{~g} \mathrm{~m}^{-2} \mathrm{~d}^{-1}$. Biocompatibility tests through cells viability and proliferation on the human skin fibroblast cell (CRL2522) revealed that GG-VCO3 film is noncytotoxic to the cells with proliferation which recorded an increase at $14 \%$ after incubation for $72 \mathrm{~h}$ rather than for $24 \mathrm{~h}$. Meanwhile, in vitro qualitative and quantitative antibacterial study of GG-VCO films against Gram-positive (Staphylococcus aureus and Staphylococcus epidermidis) and Gram-negative (Pseudomonas aeruginosa and Proteus mirabilis) bacteria showed that VCO possess weak antibacterial effect. This study has generated the fundamental knowledge of gellan gum VCO composite films which could be used and further explored for in vivo studies in an appropriate animal wound model with enhanced properties for the development of wound dressing applications.

\section{Conflict of Interests}

The authors declare that there is no conflict of interests regarding the publication of this paper.

\section{Acknowledgments}

The authors wish to thank Universiti Malaysia Terengganu (UMT) for financial assistance under internal research grant (TPM, Grant no. 68006/2012/46) and the Institute of Biotechnology Marine (UMT) for providing the facilities for undertaking this work.

\section{References}

[1] K. A. Mat Amin, K. J. Gilmore, J. Matic et al., "Polyelectrolyte complex materials consisting of antibacterial and cell-support- ing layers," Macromolecular Bioscience, vol. 12, no. 3, pp. 374382, 2012.

[2] C. J. Ferris, K. J. Gilmore, S. Beirne, D. McCallum, G. G. Wallace, and M. In Het Panhuis, "Bio-ink for on-demand printing of living cells," Biomaterials Science, vol. 1, no. 2, pp. 224-230, 2013.

[3] M.-W. Lee, H.-J. Chen, and S.-W. Tsao, "Preparation, characterization and biological properties of Gellan gum films with 1-ethyl-3-(3-dimethylaminopropyl)carbodiimide cross-linker," Carbohydrate Polymers, vol. 82, no. 3, pp. 920-926, 2010.

[4] B. N. Singh and K. H. Kim, "Effects of divalent cations on drug encapsulation efficiency of deacylated gellan gum," Journal of Microencapsulation, vol. 22, no. 7, pp. 761-771, 2005.

[5] C. Wang, Y. Gong, Y. Lin, J. Shen, and D.-A. Wang, "A novel gellan gel-based microcarrier for anchorage-dependent cell delivery," Acta Biomaterialia, vol. 4, no. 5, pp. 1226-1234, 2008.

[6] J. T. Oliveira, T. C. Santos, L. Martins et al., "Gellan gum injectable hydrogels for cartilage tissue engineering applications: in vitro studies and preliminary in vivo evaluation," Tissue Engineering-Part A, vol. 16, no. 1, pp. 343-353, 2010.

[7] A. M. Smith, R. M. Shelton, Y. Perrie, and J. J. Harris, "An initial evaluation of gellan gum as a material for tissue engineering applications," Journal of Biomaterials Applications, vol. 22, no. 3, pp. 241-254, 2007.

[8] K. G. Nevin and T. Rajamohan, "Effect of topical application of virgin coconut oil on skin components and antioxidant status during dermal wound healing in young rats," Skin Pharmacology and Physiology, vol. 23, no. 6, pp. 290-297, 2010.

[9] S. Intahphuak, P. Khonsung, and A. Panthong, "Anti-inflammatory, analgesic, and antipyretic activities of virgin coconut oil," Pharmaceutical Biology, vol. 48, no. 2, pp. 151-157, 2010.

[10] Z. A. Zakaria, M. N. Somchit, A. M. Mat Jais, L. K. Teh, M. Z. Salleh, and K. Long, "In vivo antinociceptive and anti-inflammatory activities of dried and fermented processed virgin coconut oil," Medical Principles and Practice, vol. 20, no. 3, pp. 231-236, 2011.

[11] M. Shilling, L. Matt, E. Rubin et al., "Antimicrobial effects of virgin coconut oil and its medium-chain fatty acids on clostridium difficile," Journal of Medicinal Food, vol. 16, no. 12, pp. 10791085, 2013.

[12] C. L. Hawkins and M. J. Davies, "Degradation of hyaluronic acid, poly- and monosaccharides, and model compounds by hypochlorite: evidence for radical intermediates and fragmentation," Free Radical Biology and Medicine, vol. 24, no. 9, pp. 1396-1410, 1998.

[13] U. N. Wanasundara, F. Shahidi, and C. R. Jablonski, "Comparison of standard and NMR methodologies for assessment of oxidative stability of canola and soybean oils," Food Chemistry, vol. 52, no. 3, pp. 249-253, 1995.

[14] A. Rohman, Y. B. Che Man, A. Ismail, and P. Hashim, "Application of FTIR spectroscopy for the determination of virgin coconut oil in binary mixtures with olive oil and palm oil," JAOCS, Journal of the American Oil Chemists' Society, vol. 87, no. 6, pp. 601-606, 2010.

[15] X. Xu, B. Li, J. F. Kennedy, B. J. Xie, and M. Huang, "Characterization of konjac glucomannan-gellan gum blend films and their suitability for release of nisin incorporated therein," Carbohydrate Polymers, vol. 70, no. 2, pp. 192-197, 2007.

[16] P. K. Binsi, C. N. Ravishankar, and T. K. Srinivasa Gopal, "Development and characterization of an edible composite film based on chitosan and virgin coconut oil with improved moisture sorption properties," Journal of Food Science, vol. 78, no. 4, pp. E526-E534, 2013. 
[17] S. R. Sudhamani, M. S. Prasad, and K. Udaya Sankar, "DSC and FTIR studies on Gellan and polyvinyl alcohol (PVA) blend films," Food Hydrocolloids, vol. 17, no. 3, pp. 245-250, 2003.

[18] M. Milas, X. Shi, and M. Rinaudo, "On the physicochemical properties of gellan gum," Biopolymers, vol. 30, no. 3-4, pp. 451464, 1990.

[19] R. Chandrasekaran and A. Radha, "Molecular architectures and functional properties of gellan gum and related polysaccharides," Trends in Food Science and Technology, vol. 6, no. 5, pp. 143-148, 1995.

[20] Z. Z. E. Sikorski and A. Kolakowska, Chemical and Functional Properties of Food Lipids, CRC Press, Boca Raton, Fla, USA, 2003.

[21] C. L. Silva, J. C. Pereira, A. Ramalho, A. A. C. C. Pais, and J. J. S. Sousa, "Films based on chitosan polyelectrolyte complexes for skin drug delivery: development and characterization," Journal of Membrane Science, vol. 320, no. 1-2, pp. 268-279, 2008.

[22] J. T. Oliveira, L. Martins, R. Picciochi et al., "Gellan gum: a new biomaterial for cartilage tissue engineering applications," Journal of Biomedical Materials Research Part A, vol. 93, no. 3, pp. 852-863, 2010.

[23] P. Wu, A. C. Fisher, P. P. Foo, D. Queen, and J. D. S. Gaylor, "In vitro assessment of water vapour transmission of synthetic wound dressings," Biomaterials, vol. 16, no. 3, pp. 171-175, 1995.

[24] C. G. T. Neto, J. A. Giacometti, A. E. Job, F. C. Ferreira, J. L. C. Fonseca, and M. R. Pereira, "Thermal analysis of chitosan based networks," Carbohydrate Polymers, vol. 62, no. 2, pp. 97-103, 2005.

[25] J. Ostrowska-Czubenko and M. Gierszewska-Druzyńska, "Effect of ionic crosslinking on the water state in hydrogel chitosan membranes," Carbohydrate Polymers, vol. 77, no. 3, pp. 590-598, 2009.

[26] F. Freitas, V. D. Alves, J. Pais et al., "Characterization of an extracellular polysaccharide produced by a Pseudomonas strain grown on glycerol," Bioresource Technology, vol. 100, no. 2, pp. 859-865, 2009.

[27] F. Lina, Z. Yue, Z. Jin, and Y. Guang, "Bacterial cellulose for skin repair materials," in Biomedical Engineering-Frontiers and Challenges, pp. 249-274, 2011.

[28] Y.-W. Wang, Q. Wu, and G.-Q. Chen, "Reduced mouse fibroblast cell growth by increased hydrophilicity of microbial polyhydroxyalkanoates via hyaluronan coating," Biomaterials, vol. 24, no. 25, pp. 4621-4629, 2003.

[29] D. E. Discher, P. Janmey, and Y.-L. Wang, "Tissue cells feel and respond to the stiffness of their substrate," Science, vol. 310, no. 5751, pp. 1139-1143, 2005.

[30] K. Hatano, H. Inoue, T. Kojo et al., "Effect of surface roughness on proliferation and alkaline phosphatase expression of rat calvarial cells cultured on polystyrene," Bone, vol. 25, no. 4, pp. 439-445, 1999.

[31] D. Campoccia, C. R. Arciola, M. Cervellati, M. C. Maltarello, and L. Montanaro, "In vitro behaviour of bone marrow-derived mesenchymal cells cultured on fluorohydroxyapatite-coated substrata with different roughness," Biomaterials, vol. 24, no. 4, pp. 587-596, 2003.

[32] A. N. Z. Limited, "New Zealand datasheet: arrow-norfloxacin," A. N. Z. Limited, Ed., 2013.

[33] D. O. Ogbolu, A. A. Oni, O. A. Daini, and A. P. Oloko, "In vitro antimicrobial properties of coconut oil on Candida species in Ibadan, Nigeria," Journal of Medicinal Food, vol. 10, no. 2, pp. 384-387, 2007.
[34] G. Bergsson, J. Arnfinnsson, Ó. Steingrímsson, and H. Thormar, "In vitro killing of Candida albicans by fatty acids and monoglycerides," Antimicrobial Agents and Chemotherapy, vol. 45, no. 11, pp. 3209-3212, 2001.

[35] M. K. M. Nair, P. Vasudevan, T. Hoagland, and K. Venkitanarayanan, "Inactivation of Escherichia coli O157:H7 and Listeria monocytogenes in milk by caprylic acid and monocaprylin," Food Microbiology, vol. 21, no. 5, pp. 611-616, 2004.

[36] D. Altiok, E. Altiok, and F. Tihminlioglu, "Physical, antibacterial and antioxidant properties of chitosan films incorporated with thyme oil for potential wound healing applications," Journal of Materials Science: Materials in Medicine, vol. 21, no. 7, pp. 22272236, 2010.

[37] R. J. W. Lambert, P. N. Skandamis, P. J. Coote, and G.-J. E. Nychas, "A study of the minimum inhibitory concentration and mode of action of oregano essential oil, thymol and carvacrol," Journal of Applied Microbiology, vol. 91, no. 3, pp. 453-462, 2001. 

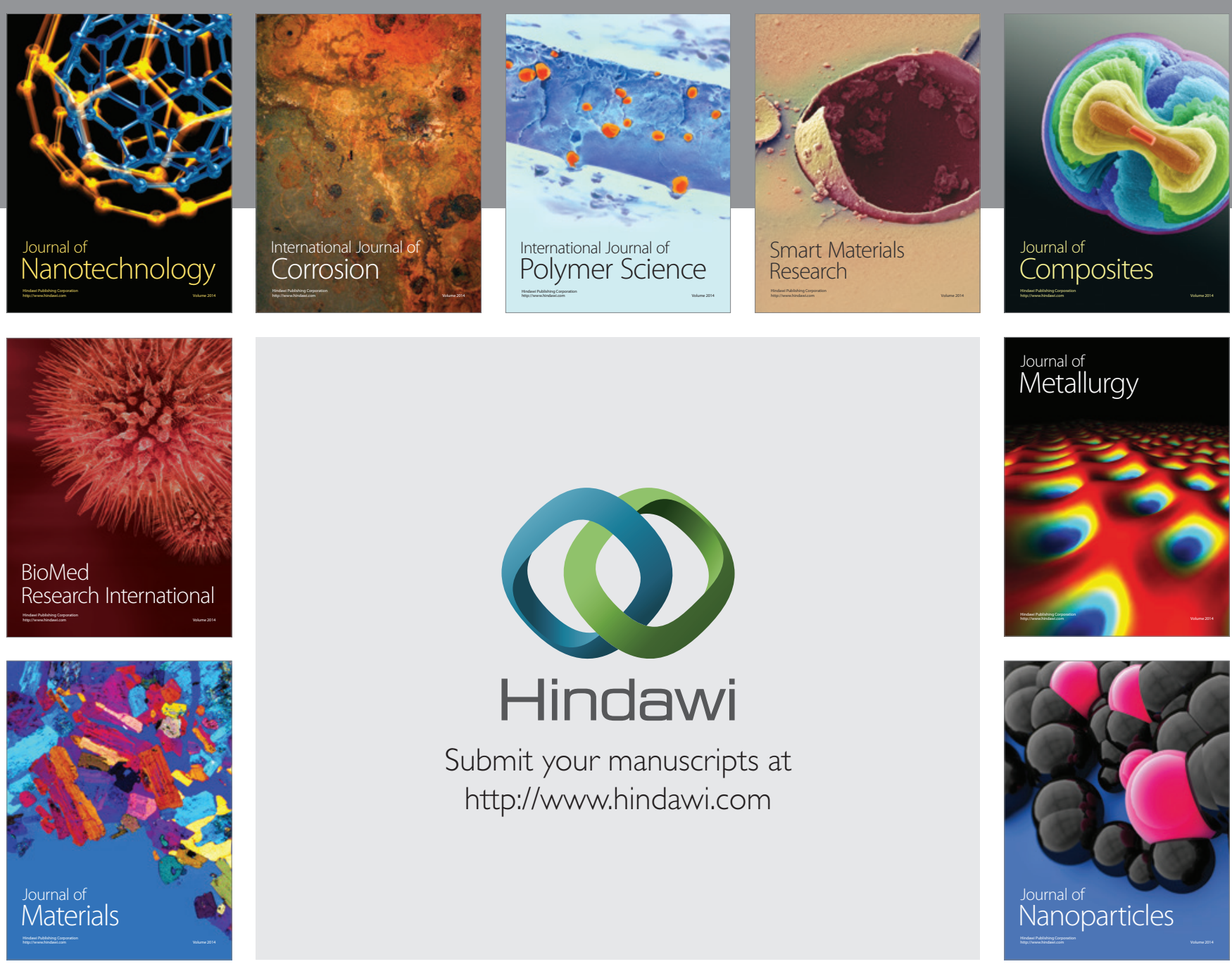

Submit your manuscripts at http://www.hindawi.com
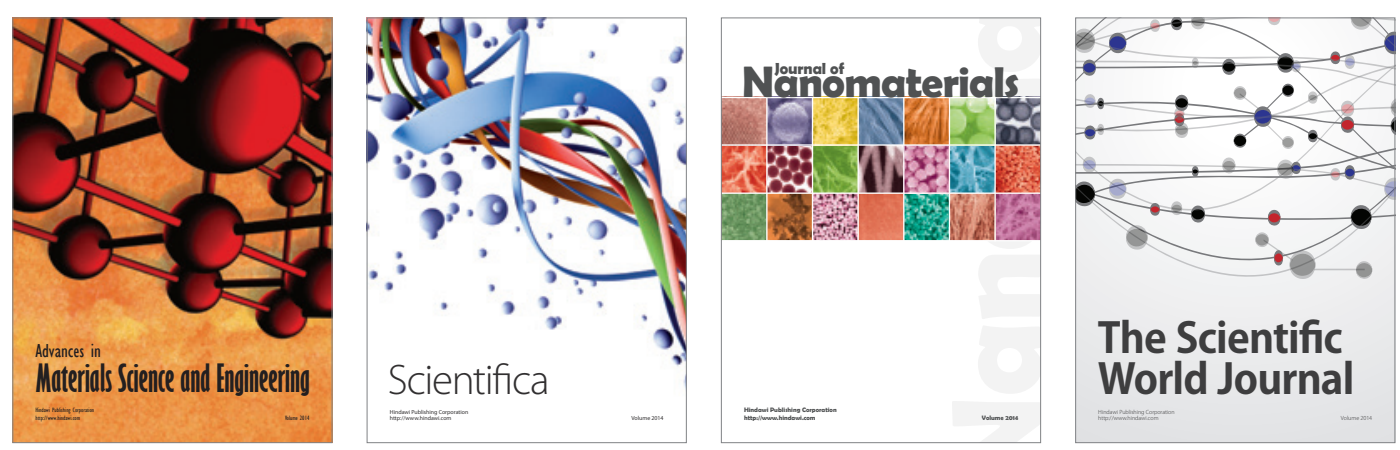

\section{The Scientific World Journal}
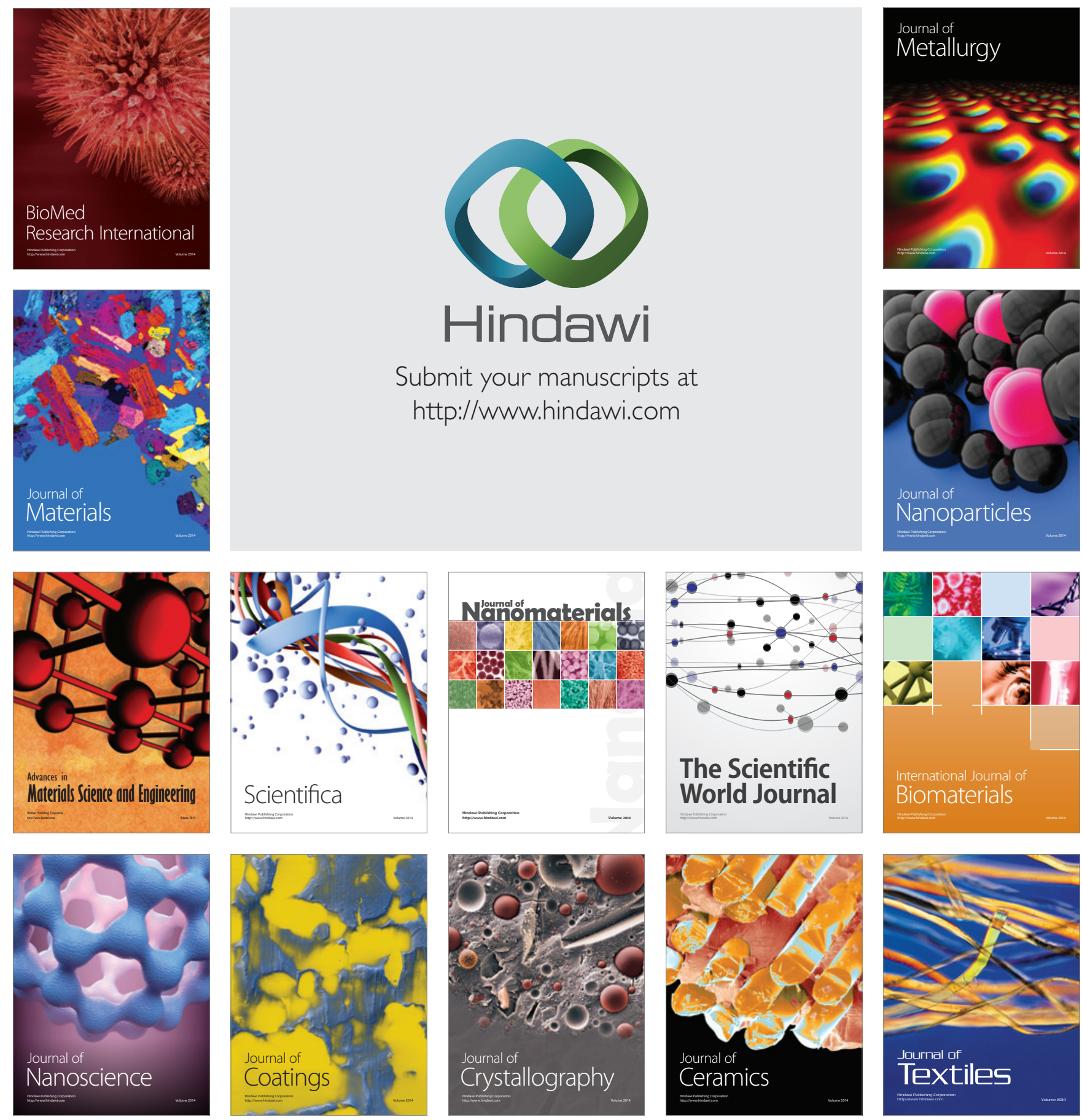